\title{
Corneal Dystrophy Adds to the Frustration of a Dry Eye Patient
}

\author{
Michelle Zakem \\ Ecole d'optométrie, \\ Université de Montréal

\section{Etty Bitton,} \\ OD, MSc, FAAO, FBCLA \\ Ecole d'optométrie, \\ Université de Montréal
}

\begin{abstract}
PURPOSE

This case report highlights how epithelial basement membrane dystrophy (EBMD), coupled with dry eye, can contribute to symptoms of unstable vision and discomfort. This report also reviews corneal dystrophies and offers eye care practitioners (ECPs) clinical pearls for identifying key features.
\end{abstract}

\section{CASE REPORT}

A 62-year-old Caucasian female presented for a dry eye evaluation due to fluctuating vision and longstanding ocular discomfort, despite ocular lubrication. Anterior segment examination revealed Meibomian gland dysfunction (MGD), upper lid margin staining (ULMS) and anterior blepharitis. The patient was unaware of a pre-existing EBMD and this lack of knowledge contributed to her frustration concerning her unstable vision, which she had solely attributed to her glasses. Management included warm compresses for MGD and targeted preservative-free artificial tears for ULMS and EBMD. Photographs were essential for educating the patient with respect to the irregularities of the ocular surface and its effect on vision. This provided a deeper understanding of the multifactorial nature of her symptoms.

\section{CONCLUSION}

Unstable and/or poor vision is among the main reasons why patients consult ECPs and it can be difficult to identify contributory factors. This report highlights that additional chair time may be warranted to educate patients on the multifactorial nature of dry eye and the complexities of corneal dystrophy.

\section{CORRESPONDING AUTHOR \\ Etty Bitton \\ Email: etty.bitton@umontreal.ca}

DISCLOSURES

None that are associated with this manuscript

\section{KEYWORDS}

corneal dystrophy, epithelial basement membrane dystrophy, dry eye 


\section{INTRODUCTION}

Fluctuating vision can be very frustrating for a patient due to its transient and unpredictable nature, which can affect daily tasks, such as reading, driving, and computer use. Common factors that may contribute to fluctuating vision include ocular-surface anomalies (e.g., corneal dystrophy, dry eye), diabetes and hormonal changes (e.g., during pregnancy). ${ }^{1}$ Poor vision may also be due to uncorrected refractive error, ocular media opacity (i.e., corneal, lenticular, or vitreal) and retinal conditions.

Dry eye (DE) disease is a widely prevalent condition, ${ }^{2}$ which is often accompanied by symptoms of ocular discomfort and vision disturbances, ${ }^{3}$ that affects many aspects of a patient's quality of life. ${ }^{4-6}$ Fluctuating vision and ocular discomfort are major reasons why patients consult eye care practitioners (ECP).,

The cornea needs to remain clear for proper vision. However, in some cases, alterations to any of the layers of the cornea can affect its transparency and ultimately its function. Corneal dystrophies are a group of genetic disorders that cause alterations to the cornea and affect its transparency. ${ }^{8,9}$ Corneal dystrophies arise from a progressive accumulation of abnormal material in any of the layers of the cornea, without inflammation, infection, or neovascularization. ${ }^{1,10}$, ${ }^{11}$ Since most corneal dystrophies follow an autosomal dominant inheritance pattern, the examination of family members can be useful for confirming the diagnosis. ${ }^{1,10,12,13}$ These dystrophies are progressive in nature, bilateral, but not always symmetrical, ${ }^{1,9,11,12}$ and, depending on the layer of the cornea affected, may or may not lead to vision changes. ${ }^{10,11,13}$

Traditionally, corneal dystrophies are classified by the anatomical location of the opacity; i.e., anterior (epithelium/ Bowman's layer), stromal or endothelial. While some are encountered more commonly than others, Table $1^{12-17}$ summarizes corneal dystrophies according to their effect on vision, which may assist ECPs in differentiating among them.

Table 1: Corneal Dystrophies ${ }^{6-11}$

\begin{tabular}{|c|c|c|}
\hline Tissue Affected & Dystrophy & Effect on vision \\
\hline \multirow{6}{*}{ Anterior } & $\begin{array}{l}\text { Epithelial Basement Membrane Dystrophy (EBMD) } \\
\text { (Map-Dot-Fingerprint) }\end{array}$ & Normal or reduced (sometimes impaired) \\
\hline & Meesmann Dystrophy & Not usually affected but may rarely decrease \\
\hline & Lisch Dystrophy & Sometimes impaired (20/25 to $20 / 40)$ \\
\hline & $\begin{array}{l}\text { Gelatinous droplike corneal dystrophy } \\
\text { (Familial subepithelial corneal amyloidosis)* }\end{array}$ & $\begin{array}{l}\text { Marked visual impairment } \\
\text { (reduced in first decade) }\end{array}$ \\
\hline & Reis-Bücklers Dystrophy & $\begin{array}{l}\text { Progressive visual impairment, } \\
\text { marked by } 2^{\text {nd }}-3^{\text {rd }} \text { decade }\end{array}$ \\
\hline & Thiel-Behnke dystrophy & $\begin{array}{l}\text { Progressive visual impairment marked } \\
\text { by } 2^{\text {nd }}-3^{\text {rd }} \text { decade }\end{array}$ \\
\hline \multirow{5}{*}{ Stromal } & Lattice Dystrophy Type 1 & $\begin{array}{l}\text { Progressive visual impairment, } \\
\text { marked by } 3^{\text {rd }}-4^{\text {th }} \text { decade }\end{array}$ \\
\hline & Lattice Dystrophy Type 2 & Vision usually normal until $6^{\text {th }}-7^{\text {th }}$ decade \\
\hline & Granular Dystrophy & $\begin{array}{l}\text { Vision good }<40 \mathrm{y} \text {, progressive visual } \\
\text { impairment afterwards }\end{array}$ \\
\hline & Macular Dystrophy & Severe visual impairment by $3^{\text {rd }}-4^{\text {th }}$ decade \\
\hline & Schnyder Crystalline Dystrophy & $\begin{array}{l}\text { Not usually affected } \\
\text { (but might be occasionally) }\end{array}$ \\
\hline \multirow{3}{*}{ Endothelial } & Fuchs Dystrophy & $\begin{array}{l}\text { Progressive visual impairment evolving } \\
\text { in marked reduction (worse in the } \\
\text { morning and improves during the day) }\end{array}$ \\
\hline & Posterior Polymorphous Dystrophy & Rarely progressive visual impairment \\
\hline & Congenital Hereditary Endothelial Dystrophy & Blurred vision (worse in the morning) \\
\hline
\end{tabular}

*May also be classified as stromal 
This case report describes a symptomatic patient who was frustrated and unclear as to the source of her unstable vision and discomfort, which had several etiologies, including DE and corneal dystrophy.

\section{CASE REPORT}

A 62-year-old Caucasian female was referred to a DE clinic due to longstanding symptoms of fluctuating vision and DE. Her most recent eye exam was 5 months prior; a refractive change was noted and new glasses were prescribed. Her general health revealed a history of fibromyalgia, rheumatoid arthritis, hypertension, hypothyroidism and depression. Medication use included Diovan HCT $^{*}$ (Novartis) for her hypertension, Synthroid (Abbvie) for her thyroid, Xanax (Pfizer) for her depression, vitamins (E and C) and omega-3 supplements. Her ocular history revealed longstanding complaints of $\mathrm{DE}$, fluctuating vision, pain, irritation and a gritty sensation in both eyes. The patient also reported dryness of the mouth, throat, and nose; she tested negative for Sjögren's syndrome. Additionally, macular drusen were noted and age-related macular degeneration (ARMD) was diagnosed, for which she takes vitamins (Vitalux', ALCON) and is being followed by a retinal specialist. Mild nuclear sclerosis (grade 1) was noted in both eyes. The patient reported using artificial tears (Systane ULTRA, ALCON) 8X/day and an ocular ointment at bedtime (Liposic gel, Bausch + Lomb) to address her ocular discomfort. She remained unsatisfied with her vision despite her new glasses and continued to report ocular discomfort.

A comprehensive DE evaluation revealed severe symptoms (score of 87.5/100) using the Ocular Surface Disease Index (OSDI) questionnaire. Other tear tests were performed and the results are summarized in Table 2; most values were within normal limits. Distance acuities were similar to those reported at the annual eye exam (OD 6/7.5 ${ }^{+2}$; OS $6 / 6^{+2}$; OU $6 / 6^{-1}$ ). The near acuity revealed less than optimal results (OD $0.8 \mathrm{M}$; OS $1.0 \mathrm{M}$ at $40 \mathrm{~cm}$ using a near point card), which differed from the results at her check-up 5 months previously (OD 0.37; OS $0.50 \mathrm{M}$ at $50 \mathrm{~cm}$ ).

Table 2: Clinical findings of DE exam

\begin{tabular}{|l|l|}
\hline Tests & Clinical Findings \\
\hline OSDI questionnaire & $87.5 / 100$ \\
\hline Osmolarity (TearLab) & OD $288 \mathrm{mOsml} / \mathrm{L} \quad$ OS $291 \mathrm{mOsml} / \mathrm{L}$ \\
\hline Cotton Thread Test & OD $34 \mathrm{~mm} / 15 \mathrm{sec} \quad$ OS $36 \mathrm{~mm} / 15 \mathrm{sec}$ \\
\hline Tear meniscus height & $0.2 \mathrm{~mm}$ OU \\
\hline Eyelid margin & Telangiectasia OU \\
\hline Lashes & Cylindrical dandruff OU \\
\hline Meibomian glands & Yellow, liquid secretions, non-linear with missing glands OU \\
\hline Corneal staining & No defects noted OU \\
\hline Bulbar Conjunctival Staining & No defects noted OU \\
\hline Palpebral Conjunctival Staining & ULMS $<20 \%$ along the full length, OU \\
\hline Tear Break Up Time (TBUT) & OD 3 sec \\
\hline Endothelial cell count & OD 2367 cells $/ \mathrm{mm}{ }^{2} \quad$ OS 2423 cells $/ \mathrm{mm}^{2}$ \\
\hline
\end{tabular}

A detailed anterior segment evaluation revealed redness (telangiectasia) along the eyelid margin, clear gelatinous deposits at the base of a few lashes resembling cylindrical dandruff (CD) and several differently shaped translucent corneal opacities in both eyes. Epilation was performed on the lashes that had CD and a microscopic evaluation confirmed the presence of Demodex folliculorum, a common lash mite. Meibomian gland assessment revealed difficulty with expression along with yellow, liquid secretions. Meibography (Meiboscan, 5M Keratograph, Oculus) revealed non-linear and partially filled Meibomian glands in all four eyelids. Ocular staining revealed upper lid margin staining (ULMS) along the full length of the upper palpebral conjunctiva, with a $20 \%$ thickness profile (Table 2 ). 
The corneal opacities varied with respect to both shape and size, and could be described as irregular gray geographic patches (resembling ground-glass) and clustered, whorl-like patterns resembling a fingerprint (Figs. 1 and 2). These were observed under white illumination with an oblique broad beam, but were more evident with fluorescein instillation (Fig. 3). No epithelial defects were noted in either eye. While both eyes presented opacities in the pupillary axis, the dystrophy was more advanced in the left eye, which partly contributed to the reduced near acuity. The corneal opacities were photodocumented to establish a baseline and to educate the patient.

Figure 1: Map (below) and Fingerprint (above) corneal opacities apparent in the right eye

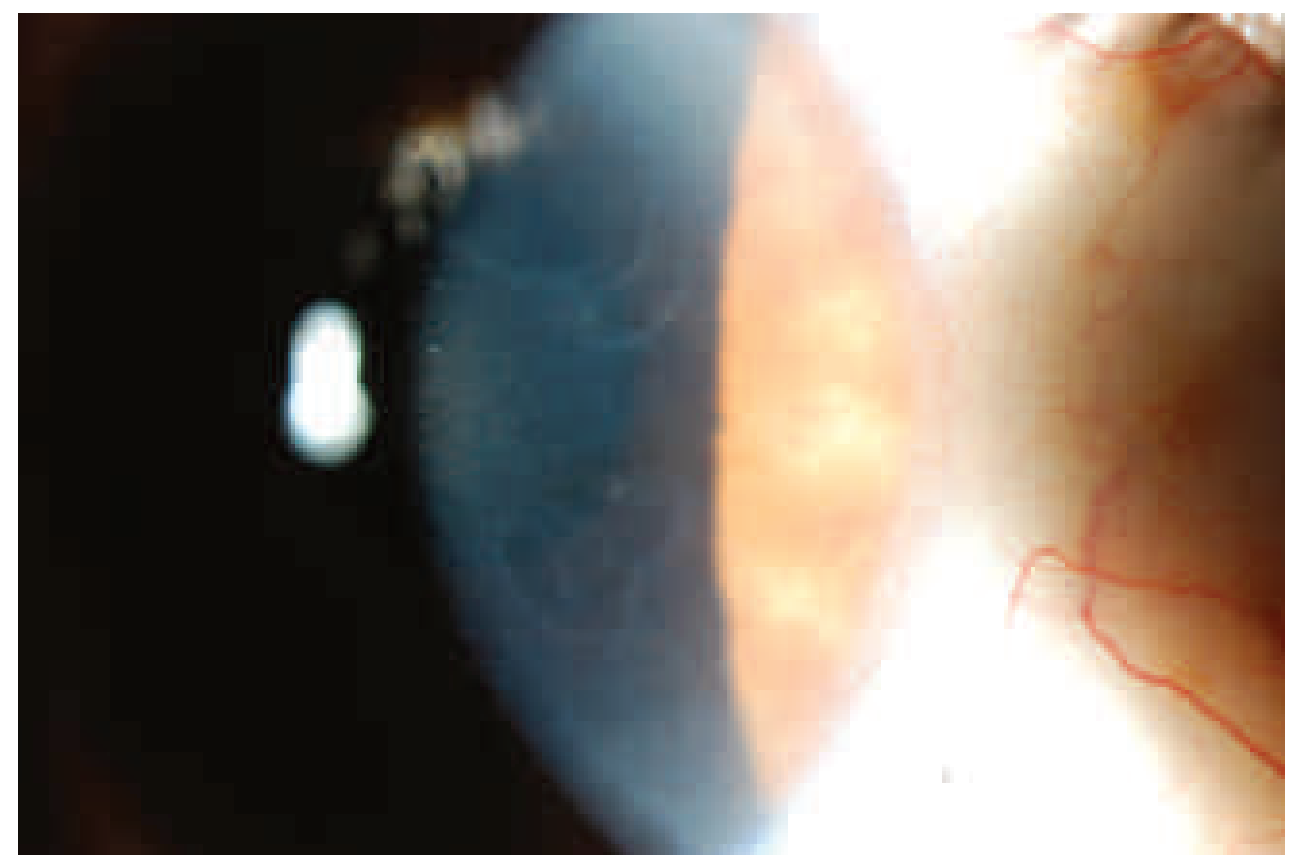

Diagnosis included evaporative DE secondary to MGD, anterior blepharitis secondary to Demodex, and ULMS. Due to the clinical presentation of corneal opacities, a primary diagnosis of epithelial basement membrane dystrophy (EBMD) was established.

Management for MGD included daily warm compresses using a face towel for 5-10 minutes followed by ocular massage. Since the patient did not own a microwave, eyelid warming masks were not a feasible option. Consequently, patient education was important to explain how the warm face cloth needed to be alternated with another every 1-2 minutes to maintain heat on the eyelids. ${ }^{18,19}$ She was encouraged to continue with omega-3 supplementation.

The patient was educated on EBMD, including its permanent nature and associated fluctuating vision and the possibility of recurrent corneal erosions (RCE). Despite this explanation, the patient was still convinced that her subpar vision was due to her new glasses. Management was aimed at decreasing the fluctuating vision, reestablishing a smooth refractive surface, and limiting friction between the lid and the corneal surface. Hence, a non-preserved artificial tear with sodium hyaluronate (I-Drop Pur Gel, I-Med Pharma Inc.) was recommended at least 4X/day to both reduce friction (ULMS) and enhance the tear layer over the irregular ocular surface (EBMD).

Since the patient was distraught over the EBMD and the fact that her dissatisfaction with her vision may be more permanent than she had anticipated, a discussion about the anterior blepharitis secondary to Demodex was delayed for a follow-up visit 4 months later. 
Figure 2: Topographical map corneal opacities present centrally in the left eye

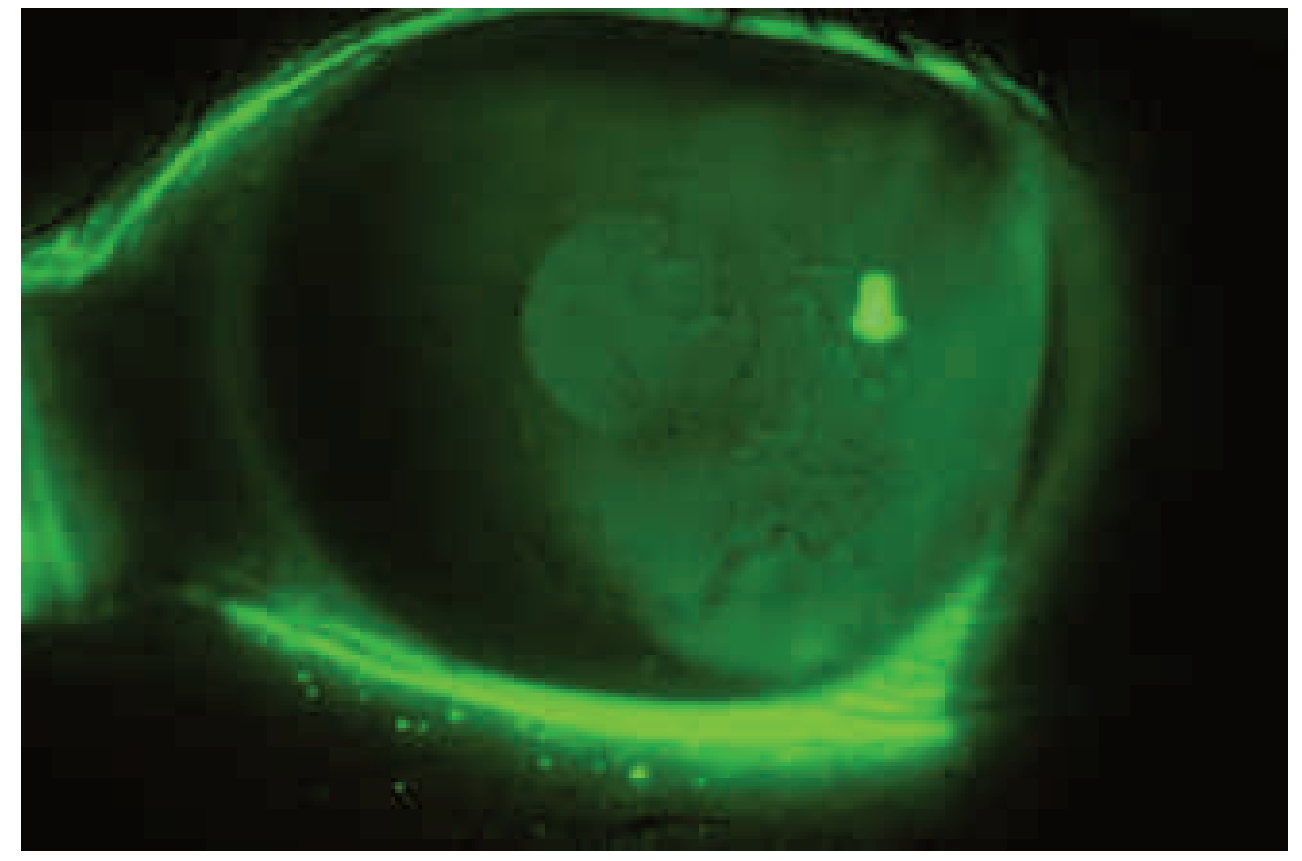

Figure 3: Fluorescein staining highlights the geographic patterns of EBMD in the left eye

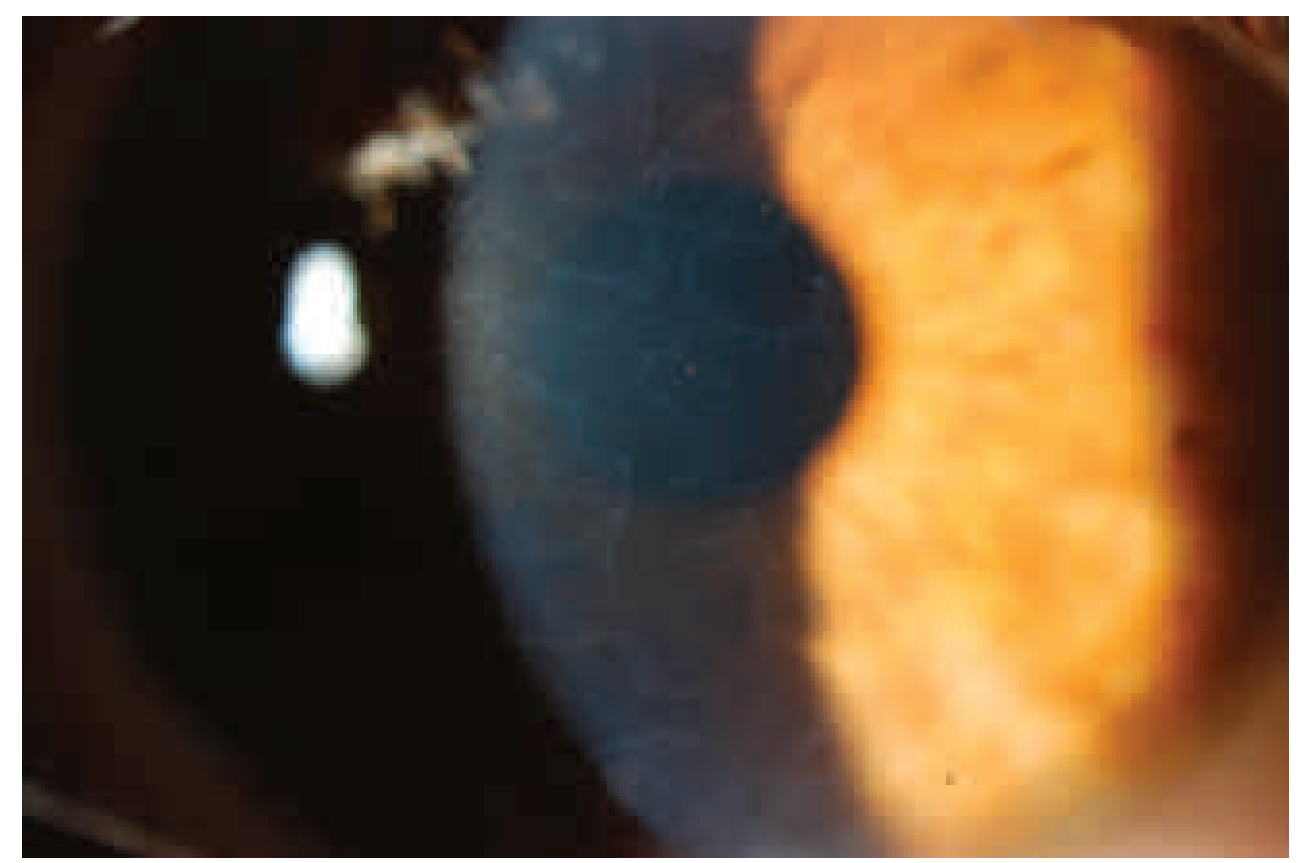


The patient was properly counseled on the contributing etiologies of her symptoms, which included discomfort and fluctuating vision. Patient education included information on EBMD, dry eyes, cataracts, and ARMD. Although she was still disgruntled, the patient left with a better understanding of the causes of her fluctuating vision and ocular discomfort.

\section{DISCUSSION}

This case exemplifies how EBMD, coupled with DE, can contribute to a patient's symptoms of unstable vision and discomfort. Patients typically assume that all vision problems are correctable. However, in this case, the patient needed to be properly educated about the multifaceted etiology of her condition, which may not be completely resolvable. Patients need to be reminded that several components of the eye are responsible for creating optimal vision, from the tear film to the retina. Consequently, any disturbances along that path may contribute to poor/unstable vision. In this case, the tear film, cornea, lens and retina were compromised, and thus extra time was dedicated to educate the patient appropriately. The patient's complaints were focused on fluctuating blurred vision, irritation and pain, despite the lack of any apparent RCE and an updated refraction. A brief discussion of corneal dystrophies with particular attention to EBMD was necessary for the patient to understand its contribution to overall vision.

EBMD is the most common corneal dystrophy.9, 16 Although EBMD can occur sporadically, there have been some cases of autosomal dominant inheritance. ${ }^{9,14,20}$ EBMD is defined by a triad of characteristic corneal changes, notably grey geographic patches (referred to as 'Map'), gray-white round or oblong opacities ('Dot'), and curvilinear refractile clustered lines ('Fingerprint'). ${ }^{15}{ }^{21}$ Hence EBMD has also been described as Map-Dot-Fingerprint dystrophy to reflect the patterns observed on the cornea, and may present some or all of these three features. ${ }^{20}$ Symptoms include blurry vision, grittiness, foreign body sensation, and pain (especially during RCE episodes). ${ }^{20,22,23}$

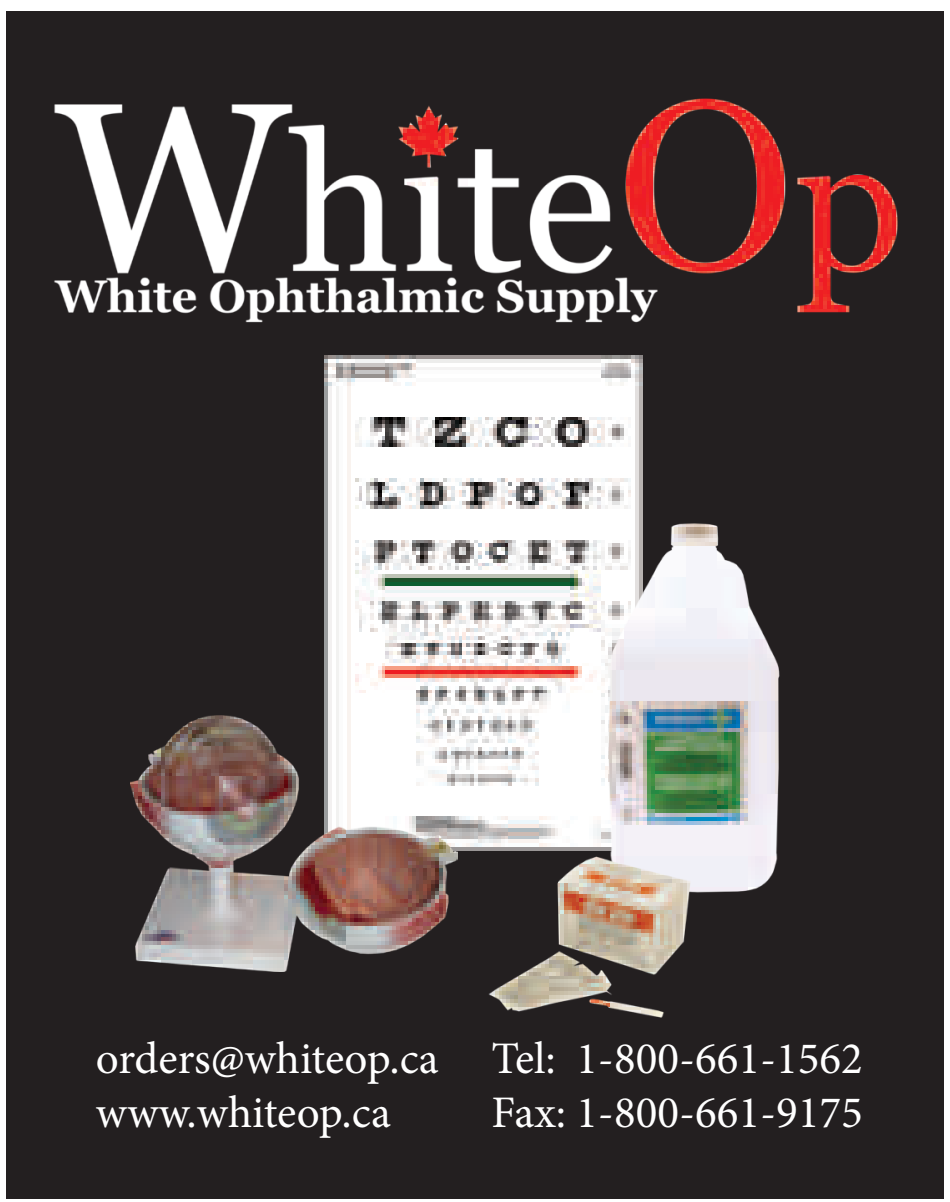


Histopathology of these opacities reveals thickening of the epithelial basement membrane with abnormal extensions into the overlying epithelium. ${ }^{12,20}$ With the use of fluorescein, these elevated areas appear as negative staining and contribute to decreased tear-film stability. ${ }^{14,24}$ Furthermore, these projections inhibit the normal surface migration of maturing epithelial cells, resulting in cysts containing cellular debris from the degenerating cells. ${ }^{12}$ Epithelial cells have hemidesmosomes to reinforce their anchoring to the basement membrane. In EBMD, epithelial cells anterior to the abnormal basement membrane are unable to form hemidesmosomes, which causes poor adherence. ${ }^{20}$ Due to this frail attachment, the epithelial layer can easily be separated, causing RCE in 10\% of these patients; asymptomatic patients can quickly become severely symptomatic., ${ }^{1,21}$

When differentiating between corneal opacities, an ECP will consider age of onset, effect on vision and location and appearance of opacities to render a diagnosis. Age of onset is a poor parameter to distinguish between epithelial dystrophies as they all typically occur by the first and/or second decade of life. ${ }^{12-14}$ EBMD, which is an exception, appears in early adulthood. ${ }^{12,14}$ Although the present patient was an adult, the age of onset was unknown and therefore could not be used to help in the differential diagnosis.

The effect on vision can be used to distinguish between corneal dystrophies (Table 1). Reis-Bücklers and ThielBehnke dystrophies, for example, may be associated with a marked reduction in acuity, while EBMD and Meesmann dystrophy have the potential to impact vision. ${ }^{12,13}$ However, in this patient, fluctuating vision was a poor differentiating indicator because there were other contributing factors, such as DE, cataracts and ARMD. Therefore, in her case, anterior and posterior segment photography was warranted along with strict follow-up to best identify which condition will progressively affect her vision.

Symptoms of ocular discomfort and pain, which this patient reported, also may occur in DE and corneal dystrophies (with the presence of RCE). This patient had no visible RCE at the time of consultation, yet she reported pain, which may be linked to her ocular-surface dryness. Furthermore, the possibility of RCE was discussed, along with the associated abrupt onset of pain, which may occur and prompt consultation. Although RCEs are possible in any of the epithelial dystrophies, ${ }^{13,25}$ people may not consult an ECP due to the variability in pain sensation and discomfort that they may experience.

Consequently, age of onset, effect on vision, and pain are not reliable indicators for identifying a corneal pathology. As a result, the location and appearance of the opacities remain the principal factors in the diagnosis of epithelial dystrophies..$^{25}$ It is unlikely that an average practitioner would have clinical experience with the full scope of corneal dystrophies, unless in a corneal specialty practice. Hence, an atlas would be a useful resource for clarifying the clinical presentation of opacities. Table $3^{1,13,14,21,25}$ provides some clinical pearls to associate characteristic features of corneal opacities with the related epithelial dystrophy. The present case represents a typical EBMD, with representative photographs, in that the clinical presentation included characteristic Map- and Fingerprint-like corneal opacities.

Table 3: Clinical pearls in identification of epithelial dystrophies s $^{3,7,8,13,19}$

\begin{tabular}{|l|l|l|}
\hline Feature & Location & Dystrophy \\
\hline $\begin{array}{l}\text { Map (geographic-shaped opacities) } \\
\text { Dot (putty-like opacities), Fingerprint } \\
\text { (whorl-like clustered lines) }\end{array}$ & Epithelial/diffuse & EBMD \\
\hline Epithelial vesicle of uniform shape and size & $\begin{array}{l}\text { Epithelial/concentrated in the interpalpebral } \\
\text { region }\end{array}$ & Meesmann \\
\hline $\begin{array}{l}\text { Feathery and/or flame-shaped opacities and } \\
\text { optically empty microcysts }\end{array}$ & Epithelial/diffuse & Lisch \\
\hline $\begin{array}{l}\text { Fine reticular opacification } \\
\text { (linear, ring-like, or alveolar patterns) }\end{array}$ & $\begin{array}{l}\text { Subepithelial/most dense in central or mid- } \\
\text { periphery (extreme periphery is spared) }\end{array}$ & Reis-Bücklers \\
\hline Honeycomb patterned opacity & $\begin{array}{l}\text { Subepithelial/most dense in central or mid- } \\
\text { periphery (extreme periphery is spared) }\end{array}$ & Thiel-Behnke \\
\hline
\end{tabular}


EBMD was previously noted in the patient's chart, however the patient was unaware of the condition and its effects. In this case, the lack of knowledge could have contributed to the patient's frustration regarding her vision. Visualization of her opacities via digital photography was quite effective in solidifying her understanding of the causes of her poor vision. This further confirmed that photographs are valuable chair-side educational tools for patients. Typically, clinicians do not own anterior segment cameras. However, a smartphone can easily be propped up against the oculars of a slit lamp to facilitate anterior segment photography. ${ }^{26}$

In this patient, DE was evaporative (MGD), frictional (ULMS) and inflammatory (blepharitis). These conditions are all attracting interest in the optometric field and little is known about their pathophysiology and management. For now, treatment for this patient was limited to artificial tears and warm compresses, and an information sheet was provided to increase her understanding and compliance.

CONCLUSION

Visual impairment, whether permanent or not, is very disconcerting to patients. Consequently, an ECP needs to take time to educate their patient appropriately on contributory factors that can affect vision, such as corneal dystrophies. Although this patient initially presented with frustration regarding her vision and ocular discomfort, patient education allowed her to gain a better understanding of her conditions, especially with regard to EBMD and DE. The use of anterior segment photography proved to be a powerful tool for promoting the patient's understanding and hopefully improving compliance with the recommended management. $\bullet$

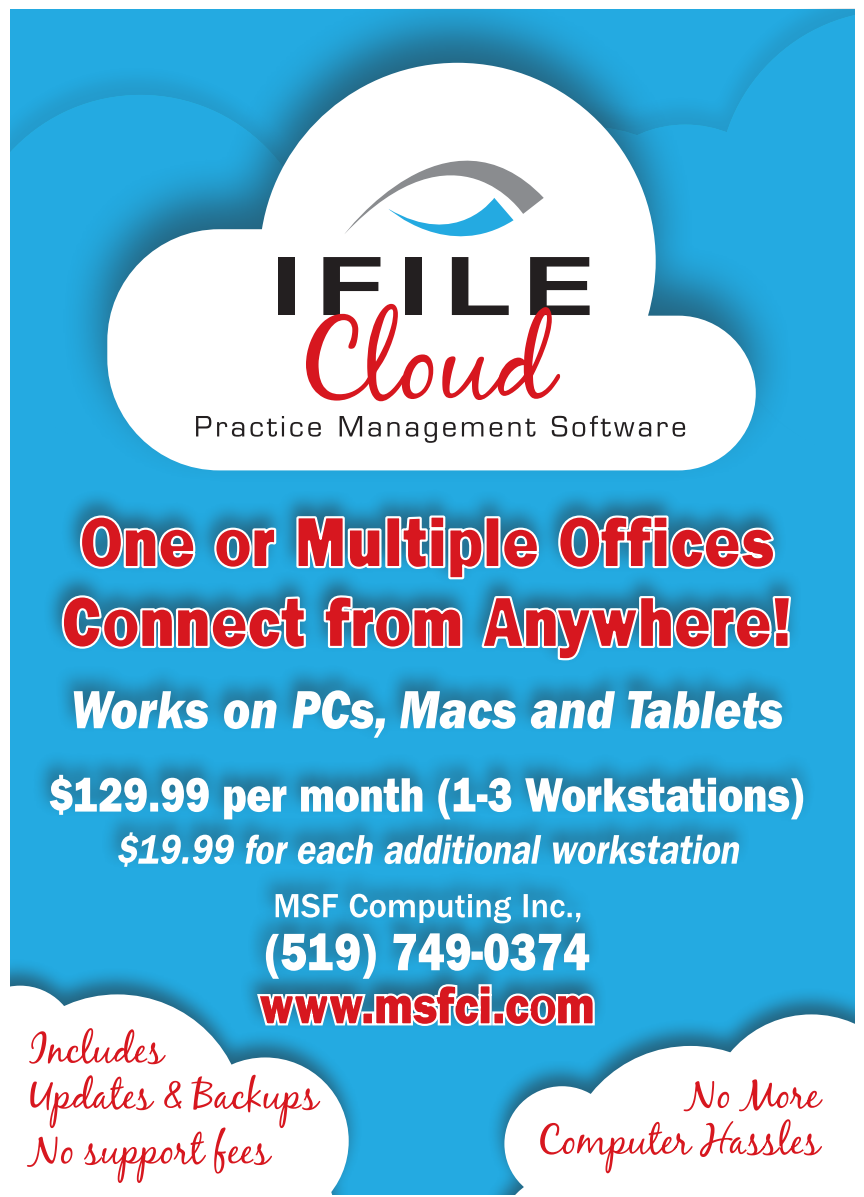




\section{References}

1. Gerstenblith AT, Rabinowitz MP. The Wills eye manual: Office and emergency room diagnosis and treatment of eye disease. 6th ed. Philadelphia: Lippincott Williams \& Wilkins; 2012.

2. The epidemiology of dry eye disease: report of the Epidemiology Subcommittee of the International Dry Eye WorkShop (2007). Ocul Surf 2007;5(2):93-107.

3. The definition and classification of dry eye disease: report of the Definition and Classification Subcommittee of the International Dry Eye WorkShop (2007). Ocul Surf 2007;5(2):75-92.

4. Baudouin C, Creuzot-Garcher C, Hoang-Xuan T, et al. Severe impairment of health-related quality of life in patients suffering from ocular surface diseases. J Fr Ophtalmol 2008;31(4):369-78.

5. Li M, Gong L, Chapin WJ, Zhu M. Assessment of vision-related quality of life in dry eye patients. Invest Ophthalmol Vis Sci 2012;53(9):5722-7.

6. Uchino M, Schaumberg DA. Dry eye disease: Impact on quality of life and vision. Curr Ophthalmol Rep 2013;1(2):51-7.

7. Lemp MA. Epidemiology and classification of dry eye. Adv Exp Med Biol 1998;438:791-803.

8. Mastropasqua L, Nubile M. Confocal microscopy of the cornea. Thorofare, NJ: Slack Incorporated; 2002. p. 19-27.

9. Kanski JJ, Bowling B. Clinical ophthalmology : a systematic approach. 7th ed. Edinburgh ; Toronto: Elsevier/Saunders; 2011. p. 212-22.

10. Boyd K. Corneal Dystrophies: American Academy of Ophthalmology; 2015 [Available from: http://www.aao.org/eye-health/diseases/ corneal-dystrophies.

11. Van C, Syed N. Epithelial-Stromal and Stromal Corneal Dystrophies: A Clinicopathologic Review: EyeRounds.org; 2015 [Available from: http:// www.eyerounds.org/cases/43-Corneal-Stromal-Dystrophies.htm.

12. Arffa RC, Grayson M. Grayson's diseases of the cornea. 4 th ed. St. Louis, MO; Toronto: Mosby; 1997. p. 413-77.
13. Klintworth GK. Corneal dystrophies. Orphanet J Rare Dis. 2009;4:7.

14. Gold DH, Lewis RA. Clinical eye atlas. Chicago, IL: AMA Press; 2002. p. 371-99.

15. Casey TA, Sharif KW. A colour atlas of corneal dystrophies and degenerations Aylesbury, England: Wolfe Publishing 1991.

16. Macsai MS, Fontes BM. Anterior segment. Rapid diagnosis in ophthalmology. Philadelphia: Mosby Elsevier; 2008.

17. Krachmer JH, Mannis MJ, Holland EJ. Cornea. 1. 2nd ed. Philadelphia; Toronto: Elsevier Mosby; 2005.

18. Bitton E, Lacroix Z, Leger S. In-vivo heat retention comparison of eyelid warming masks. Cont Lens Anterior Eye. 2016;39(4):311-5.

19. Blackie CA, Solomon JD, Greiner JV, Holmes M, Korb DR. Inner eyelid surface temperature as a function of warm compress methodology. Optom Vis Sci. 2008;85(8):675-83.

20. Laibson PR. Anterior Corneal Dystrophies. In: Krachmer JH, Mannis MJ, Holland EJ, eds. Cornea. 1. 2nd ed. Philadelphia; Toronto: Elsevier Mosby; 2005. p. 897-935.

21. Kanski JJ, Kubicka-Trzaska A. Clinical ophthalmology : a selfassessment companion. Edinburgh; Toronto: Churchill Livingstone Elsevier; 2007. p. 162-8.

22. Karpecki PM, Shechtman DL. Put an end to EBMD. Review of Optometry. 2008;145(3).

23. Martinelli JR. When should you treat EBMD with PTK? Review of Optometry. 2010(March).

24. Ramsey AC. Vital stains: What you really need to know. Review of Cornea \& Contact Lenses. 2011(April).

25. Veire E. IC3D: Classifying corneal dystrophies. Review of Cornea \& Contact Lenses. 2010(June).

26. Hester C. Slit-lamp photography with a smartphone. Advanced Ocular Care. 2012;3(September/October):62-3.

\section{HELP YOUR PATIENTS DISCOVER NEW VISION CARE OPTIONS}

Our Co-Management program offers many advantages, including:

- Access to any of our 30 clinics across Canada

- A standardized Co-Management program

- Co-Management team available to facilitate patient care coordination

To book a free consultation for your patient, contact us directly at comanagement@lasikmd.com

\section{LASIKMD}

- An experienced team of surgeons who have collectively performed over 1 million procedures

- Affordable pricing starting at $\$ 490$ per eye 